\title{
ALGUNAS PRECISIONES EN TORNO A LOS INTERESES SUPRAINDIVIDUALES (COLECTIVOS Y DIFUSOS)
}

\author{
Maite Aguirrezabal Grünstein*
}

\begin{abstract}
RESUMEN: Se ha entendido que muchos de los problemas que presenta la tutela jurídica del consumidor se reducen al escaso conocimiento o voluntaria ignorancia por parte del legislador de la realidad social en que deben desenvolverse los instrumentos que él mismo articula. En este amplio contexto de avances legislativos y jurisprudenciales también se inscribe el examen de la protección jurisdiccional de los intereses supraindividuales, colectivos y difusos. La preocupación que subyace a las reflexiones teóricas y a los reclamos sociales, se centra, básicamente, en buscar los medios adecuados o las instituciones aptas que puedan ser operativizadas como mecanismos de protección y tutela de estos intereses, sobre todo cuando está de por medio la sobrevivencia misma de los seres humanos.
\end{abstract}

Palabras clave: Interés, supraindividual, colectivo, difuso, plurisubjetivo.

ABSTRACT: It has been understood that many of the problems that the consumer suffers are consequence of the scarce knowledge or voluntary ignorance of the social reality in that the instruments created by the legislator should be unwrapped. In this wide context of legislatives and jurisprudencial advances the exam of the jurisdictional protection of collective and diffuse interests is essencial. The concern that underlies to the theoretical reflections and the social reclamations, is centered, basically, in looking for the appropriate means or the capable institutions that can be operated as protective mechanisms and it guides of these interests, mainly when it is of for half the same survival of the human beings.

Key words: Interest, supraindividual, collective, diffuse, plurisubjetivo.

\section{GENERALIDADES}

La protección jurídica de los intereses colectivos y difusos nace como consecuencia de la transformación que la sociedad ha venido experimentando especialmente a partir de la Segunda Guerra Mundial, que se ha reflejado también en el surgimiento de nuevas formas de conflicto y de mecanismos que se precisan para su solución.

La sociedad contemporánea ha sido calificada como una sociedad de masas, en la que las relaciones son cada vez más complejas: hay agrupaciones de diversos tipo (partidos políticos, sindicatos, asociaciones, etc.) o simplemente individuos afectados por infracciones del ordenamiento jurídico que tiene relevancia colectiva.

Comparado con los distintos problemas jurídicos tradicionales, el de la protección jurídica de los intereses supraindividuales, especialmente en lo relativo a la protección de

\footnotetext{
* Abogada, Doctora en Derecho de la Universidad de Navarra. Profesora de Derecho Procesal de la Universidad de los Andes.
} 
los consumidores y usuarios, tiene una historia relativamente corta ${ }^{1}$. Hasta finales del siglo pasado, la figura del consumidor no tenía importancia en el orden económico y social, puesto que se pensaba que los mecanismos del mercado, dentro de un sistema de equilibrios económicos, eran capaces por sí mismos de asegurar su protección. Esta situación se vio pronto superada como consecuencia del desarrollo y desenvolvimiento económico que generó una tendencia monopolística dentro del mercado. El Estado surge entonces como representación de un poder institucionalizado y encomendado a la protección de la libertad de los sujetos en cuanto a sus relaciones económicas.

Lo anterior se manifiesta principalmente en el fenómeno de la contratación en masa, que uniforma las cláusulas contractuales y establece condiciones generales en la contratación como respuesta a la necesidad de distribuir productos o servicios homogéneos ${ }^{2}$.

Esta etapa se caracteriza también por la politización de los derechos sociales, económicos y culturales, y se desarrollan dos fenómenos que son indisociables: la emergencia de nuevos grupos sociales de particulares condiciones y la identificación y categorización de intereses que si bien se pueden determinar de pertenencia individual, en razón de su importancia colectiva se establecen como propios de esos grupos o categorías sociales y que han sido denominados por la doctrina intereses supraindividuales o transindividuales ${ }^{3}$. Se enmarcan dentro de lo que se ha conocido como derechos de tercera generación o derechos humanos de la solidaridad, encontrando su origen científico en la teoría de Karel Vasak, sobre la dimensión internacional de los derechos del hombre. En ella, junto a la reconocida distinción entre derechos civiles, políticos, económicos y culturales, habla de estos nuevos derechos, que son aquellos que proceden de una cierta concepción de la vida en comunidad, y solo se pueden realizar por la conjunción de los esfuerzos de todos los que participan en la vida social ${ }^{4}$.

\footnotetext{
${ }^{1}$ Solamente en los años sesenta se multiplican las declaraciones y normativas tendientes a la protección del consumidor. Estados Unidos fue el pionero en plasmar la defensa de los consumidores, y siguiendo el ejemplo norteamericano los países industrializados han reaccionado de forma paralela. Fue a partir del mensaje al Congreso que diera el día 19 de marzo de 1962 el presidente John F. Kennedy sobre la protección de los intereses de los consumidores con el que se inició el movimiento de protección y defensa de los mismos, y que se extendió con mucha rapidez, creándose asociaciones, doctrina y leyes especiales para esta materia. En Inglaterra destaca la Consumer Protection Act, de 1961.

2 Cfr. Rodríguez (1990) p. 402. En este mismo sentido Bonet (1989) p. 20, quien señala que "aquí opera una paradoja que, considerada en su estructura, puede explicar, bien que parcialmente, los efectos del fenómenos del consumo. Mientras que el producto se acerca al consumidor por una publicidad que se le ofrece rompiendo la frontera de la intimidad privada del ciudadano, el productor responsable del producto se aleja del consumidor, bien físicamente por el establecimiento lejano del centro de producción, bien jurídicamente por la interposición de intermediarios, lo que crea trabas en orden a la exigencia de la calidad y del cumplimiento de lo que impone la buena fe contractual".

3 Como expresa ACOSTA (1995) p. 40, "estamos en presencia de unos intereses que pertenecen a todos y cada uno de los miembros integrantes de la sociedad. Por tanto, encontramos el reconocimiento de una realidad social: la existencia de unos intereses que precisan protección jurídica y tutela procesal”. Se concluye así que las relaciones humanas son decisivas en la aparición de nuevos y distintos intereses en los que aparecen implicados diversos sectores sociales.

${ }^{4}$ Cfr. VASAK K. (1982) pp. 3-10.
} 
Los derechos que se identifican como pertenecientes a esta nueva generación tienen en común dos notas: primero, no proceden de la tradición individualista o socialista de la primera y segunda generación; y segundo, se sitúan al principio de un proceso legislativo, lo que les permitirá ser reconocidos en el futuro como derechos humanos. Su fundamento primero radica en la solidaridad, valor que recibe su elaboración teórica moderna de la mano de Durkheim. Puede ser entendida como un factor social, un principio jurídico-político y un principio jurídico-constitucional. Como valor jurídico sustentador de estos derechos, podemos definirla como "la conciencia conjunta de derechos y obligaciones, que surgiría de la existencia de necesidades comunes, de similitudes, que preceden a las diferencias sin pretender su allanamiento" 5 .

Estos intereses poseen también una dimensión social puesto que pertenecen a una colectividad de personas y solamente a estas. Intereses de masas que comportan ofensas de masas y que ponen en contraste grupos, categorías, clases de personas. Aquí se insertan los intereses de los consumidores, los intereses medioambientales, los de usuarios de servicios públicos, de los inversionistas y de todos aquellos que integran una comunidad compartiendo sus necesidades ${ }^{6}$.

La tutela individual de los derechos e intereses legítimos y, por ello, las propias estructuras procesales clásicas se muestran insuficientes para dar cumplimiento a los mandatos constitucionales y legales de promover las condiciones para que la libertad y la igualdad sean reales y efectivas para el individuo, pero también para los grupos en que este se integra. En este sentido, Mauro Cappelletti, hace ya tres décadas, anticipaba cambios importantes y "oleadas" de reforma en el ámbito del acceso a la justicia, una de las cuales estaba encaminada a asegurar la tutela jurisdiccional de ciertos derechos e intereses particulares importantes y especialmente vulnerables en las sociedades postindustriales que se basan en la masificación de la producción, de la distribución y del consumo ${ }^{7}$.

La protección de esos intereses, como señalaba Cappelletti, pone de manifiesto la insuficiencia de los mecanismos tradicionales del proceso y de la tutela jurisdiccional, y plantea el desafío de buscar nuevas formas y tipos procesales que permitan reformular y adaptar los conceptos y principios clásicos. Agrega Berizonce que, "una tutela efectiva, y no solo nominal de tales derechos "de incidencia colectiva" requiere permitir y hasta estimular el "acceso" de los representantes (públicos y privados) de aquellos grupos desorganizados, de contornos imprecisos y a menudo difíciles de precisar, admitiendo una suerte de legitimación especial y ampliada para estar en juicio por la totalidad de la clase o categoría del interés difuso que defienden. En paralelo, afirmaba, se requiere articular vías y procedimientos no menos singulares, apropiados para la tutela diferen-

\footnotetext{
5 DE LuCAS J. (1993) p. 29.

${ }^{6}$ Bujosa VAdell (1995) p. 21. Agrega el autor que "el individuo por su temor, su desconocimiento o su impotencia ante fuerzas más poderosas, como pueden ser las grandes empresas, se ve obligado para defender sus intereses, a reforzar sus vínculos de solidaridad con aquellos que ostentan intereses próximos a los suyos".

7 Cfr. Cappelletti (1995) pp. 1-40.
} 
ciada de los derechos en juego, en los que se involucran las responsabilidades de las partes, los poderes y deberes de iniciativa y de control del juez y los efectos mismos de las decisiones por el alcance particular de la cosa juzgada" . $^{\text {. }}$

El Derecho, y en particular el proceso, deben cumplir tareas hasta hace poco desconocidas, que exigen nuevos tipos de tutela. Lo anterior se deja sentir con tal fuerza que la protección del consumidor se transforma en un principio inspirador del ordenamiento jurídico que altera y modifica el principio de la autonomía de la voluntad como expresión de la libertad de contratación?

Para hacer frente a los requerimientos de estas nuevas situaciones la doctrina ha señalado que pueden adoptarse estos dos criterios: uno tradicional, que trataría de acomodar estos nuevos supuestos a los esquemas tradicionales y otro más dinámico, que parte de las soluciones de la experiencia ofrece, pero que trasciende a ámbitos más pluriformes en el tratamiento. En efecto, puede pensarse conforme al primer criterio que la summa divisio entre Derecho Público y Derecho Privado sigue vigente y que bastaría, según la distinción entre interés privado e interés público, mantener la accionabilidad de los primeros en su plano primitivo, en tanto que todo sujeto privado puede, limitándose al concreto perjuicio experimentado, solicitar el resarcimiento de los intereses sociales pretendidamente perjudicados. Para la otra postura, en algunos aspectos del Derecho la distinción entre lo público y lo privado se encuentra en crisis, por lo que debe acudirse a

\footnotetext{
8 BERIZONCE, R. (2003) pp. XV-XVI.

9 GONZÁLEZ (1991) p. 11, considera que "es un principio generalmente aceptado que los consumidores tienen necesidad de protección: sin embargo, las reglas tradicionales del Derecho no cumplen satisfactoriamente esta necesidad más que de una forma parcial. Así, por ejemplo, en virtud del principio de la autonomía de la voluntad, los consumidores se encuentran a menudo obligados por contratos que se ven forzados a aceptar, a pesar del desequilibrio de las recíprocas prestaciones. La mayoría de las soluciones que el Derecho clásico prevé (el consentimiento, la garantía por los vicios ocultos, etc.) son de escasa utilidad para los consumidores, especialmente debido a la dificultad de la prueba, los elevados costes de las acciones judiciales, etc." Así como las organizaciones de consumidores han alcanzado distintos niveles de eficacia, en la misma medida los gobiernos han respondido de distinta manera a sus presiones. En líneas generales los Estados miembros pueden subdividirse, en este aspecto en dos categorías: aquellos en los cuales los gobiernos han instituido un organismo único encargado de los asuntos del consumidor y aquellos en que dichas cuestiones son tratadas por uno o varios ministerios. Los resultados obtenidos en los Estados miembros por lo que concierne a la protección de los intereses de los consumidores difieren también en el aspecto legislativo. A nivel normativo se refleja consecuentemente toda esta evolución en diversas regulaciones, y así se destaca la Carta de Protección de los Consumidores, aprobada por la Asamblea Constitutiva del Consejo de Europa de 17 de mayo de 1973, adoptada por el Comité de Ministros el 16 de noviembre de 1976, sobre las cláusulas abusivas en los contratos concluidos por consumidores y métodos de control apropiado y el Convenio europeo sobre la responsabilidad derivada de los productos en casos de lesiones corporales o muerte y la Resolución aprobada por el Consejo de Ministros de la Comunidad Económica Europea el 14 de abril de 1975, en que afirma que "en lo sucesivo el consumidor no es considerado solamente como un comprador o un usuario de bienes o servicios para un uso personal, familiar o colectivo, sino como una persona a la que conciernen los diferentes aspectos de la vida social que pueden afectarle directa o indirectamente como consumidor". La última referencia a la protección de los intereses de los consumidores y usuarios se recoge en el Tratado de Maastricht que otorga a instancias supranacionales la posibilidad de adoptar acciones concretas para la protección de los intereses de los consumidores y usuarios como apoyo y complemento de la política llevada a cabo por cada uno de los Estados, y con todo lo que ello conlleva.
} 
soluciones conjuntas que no representarán alternativas unívocas, procurando una potenciación de todos los sujetos posibles accionantes, de manera que a la diversidad de actuaciones lesivas pudieran corresponder también diferentes alternativas o medios de defensa.

Pioneros en la defensa de estos intereses supraindividuales son los sistemas del Common Law, en especial el de las class actions del sistema norteamericano, que a su vez se funda en la equity ${ }^{10}$ y tiene antecedentes en el Bill of Peace del siglo XVII ${ }^{11}$.

En los sistemas de Civil Law, fue la legislación brasileña la primera en introducir este tipo de tutela mediante la reforma de la Ley de acción popular. Luego, la introdujo en la ley de 1985 sobre "acción civil pública", y en 1990 la perfeccionó en el Código de Defensa del Consumidor, cuyas disposiciones procesales son aplicables a la tutela de cualquier interés supraindividual. En ese mismo texto legal, creó la categoría de los intereses individuales homogéneos, cuya protección posibilita la reparación de los daños individualmente sufridos, que en el sistema de las class actions norteamericanas corresponden a las class actions for damages.

En lo que respecta a los ordenamientos jurídicos continentales, sigue asentando la tutela de manera preferente sobre la perspectiva individual, y solo recientemente empieza a disponer de instrumentos adecuados para la contemplación y tutela de intereses de naturaleza colectiva.

No obstante, existe una manifiesta falta de profundidad en el estudio de los intereses supraindividuales, ya que en muchas ocasiones este se limita a una mera descripción de lo que debe entenderse por interés difuso, o a una enunciación de los problemas que se plantea, sin que se realice un estudio preciso desde el punto de vista de la dogmática jurídica, lo que muchas veces implica incurrir en ambigüedades o imprecisiones ${ }^{12}$.

El sector doctrinal en que se desarrollan principalmente los estudios sobre el tema tienen su sede en el Derecho Procesal, ya que uno de los aspectos principales es el de la posibilidad de su ejercicio práctico en el proceso, ámbito al que se añaden las sucesivas

10 El origen de la acción colectiva se encuentra en las "Cortes de Equidad" (Equity Courts) del Reino Unido, y era una acción propia de todas las personas afectadas por un decreto cuando su número hacía imposible citarlas a todas a un juicio. David Field fue quien inició el movimiento de la reforma procesal norteamericana, que culmina en 1938 con la redacción de las Reglas Federales para el Procedimiento Civil. Pero no fue hasta 1966 cuando se reformó la regla 23 de estas Reglas Federales, que permite a los consumidores y ambientalistas entre otros, hacer valer sus derechos mediante la acción de clase. Cfr. en este punto PELLEGRINI (2003) pp. XXXII y ss.

11 El Bill of Peace se remonta a la Inglaterra del siglo XVII en la Court of Chancery, y su propósito consistía en que aquellas personas que tuvieran pequeños reclamos unificados por un mismo interés no perdieran la posibilidad de ejercitarlos.

12 Señala en este sentido CORDÓN (1989) p. 124, que en el examen de estos intereses "se discute prácticamente todo, empezando por su propia existencia como categoría jurídica autónoma”, aunque agrega en CORDÓN (1992) p. 129, que "el encuadramiento de los intereses sociales o colectivos dentro de la categoría de los intereses jurídicamente protegidos es, tal vez, uno de los problemas más importantes que se plantean en la actualidad al estudioso de la función jurisdiccional”. 
Revista Chilena de Derecho, vol. $33 \mathrm{~N}^{0} 1$, pp. 69 - 91 [2006]

AguirreZabal GrünsteIn, Maite " "Algunas precisiones en torno a los intereses supraindividuales..."

aportaciones desde las demás ramas del Derecho ${ }^{13}$. A pesar de ser el ámbito procesal uno de los principales aspectos del tema, no es el único. Este tiene un importante y necesario sustrato material, sustantivo, sobre el que deben basarse los demás aspectos de la elaboración doctrinal ${ }^{14}$.

\section{LOS INTERESES SUPRAINDIVIDUALES}

\subsection{Planteamiento GENERAL}

Como hemos señalado anteriormente, el fenómeno de la masificación ha repercutido en el ámbito jurídico produciendo nuevas relaciones entre el individuo y la sociedad. Se caracteriza por el reconocimiento y la legitimación de organizaciones intermedias que encuentran su fundamento en la solidaridad, y que rompen con las respuestas ofrecidas por un Derecho basado en el carácter individual de las situaciones jurídicas.

Los problemas comienzan con la terminología que se emplea para designarlos, puesto que se utilizan indistintamente los vocablos "interés" y "derecho"15, para los adjetivos: colectivos, sociales, de grupo, supraindividuales, transindividuales, fragmentados, etc., problema que se dificulta aún más si se agregan los derechos individuales ejercidos de modo colectivo y que son conocidos como individuales homogéneos, plurisubjetivos o pluriindividuales. Ante esta confusión terminológica, Fairén sostiene que estos intereses o derechos representan todavía un problema nuevo, incierto y equívoco ${ }^{16}$, hasta el punto se ser calificados como intereses difusos, profusos o confusos ${ }^{17}$.

El que un derecho o interés sea supraindividual significa que trasciende la esfera de lo meramente individual, está marcado por la impersonalidad y rompe con el concepto clásico de derecho subjetivo. Estos derechos "no pertenecen a una persona física o jurídica determinada, sino a una comunidad amorfa, fluida y flexible, con identidad social, pero sin personalidad jurídica" 18 .

\footnotetext{
13 Se ha señalado que nos encontramos ante un fenómeno de naturaleza interdisciplinar y que la protección de estos intereses señalados corresponde conjuntamente a varias ramas del Derecho. Al Derecho Constitucional en cuanto que difícilmente su satisfacción no implica la satisfacción correlativa de alguno de los derechos fundamentales reconocidos en las Cartas Constitucionales. También al Derecho Penal, por cuanto a este corresponde la tipificación de conductas que afectan a la salud pública, que producen daños o que perjudican el medio ambiente. El Derecho Administrativo debe establecer de acuerdo con las leyes, las condiciones y el ámbito del ejercicio de las actividades que conciernen al interés general. De aquí entonces que aparezca en la doctrina procesal entre otras posibilidades, la tendencia que busca en la atribución de legitimación a los cuerpos intermedios nuevas titularidades que permitan el ejercicio de acciones en defensa de intereses sociales y colectivos. La concepción de la acción como petición de tutela para un derecho del que el actor es o se afirma titular resulta insuficiente para articular el acceso a la justicia de las situaciones jurídicas colectivas o difusas.

${ }^{14}$ Cfr. Gutiérrez de Cabiedes (1999) pp. 62-63.

15 A este planteamiento nos referiremos a propósito de la caracterización jurídica de los intereses supraindividuales.

16 Cfr. Fairén Guillén (1990) p. 93. Creemos que lo más apropiado es utilizar el concepto genérico de intereses supraindividuales, y como especie de estos, los intereses difusos y los colectivos.

17 Cfr. Gutiérrez de Cabiedes (1990) p. 30.

18 GIDI (2003) p. 32.
} 
Las acciones para su protección han sido concebidas para la defensa de los siguientes tipos de intereses: 1) los intereses difusos, que son aquellos intereses supraindividuales de naturaleza indivisible de los que son titulares sujetos indeterminados unidos por circunstancias de hecho; 2) los intereses colectivos, que también son de naturaleza supraindividual e indivisible, pero entre los titulares de esos intereses existe algún tipo de vinculación jurídica y 3) los intereses individuales homogéneos, que son aquellos de naturaleza individual y de titularidad exclusiva pero con un origen fáctico común.

Esta triple clasificación tiene su origen en los sistemas jurídicos anglosajones y ha sido principalmente desarrollada por el Derecho brasileño ${ }^{19}$. Así, el Código de Defensa del Consumidor define en su artículo 81 estos dos tipos de intereses, y señala que son difusos los intereses "transindividuales, de naturaleza indivisible, de los que sean titulares personas indeterminadas y ligadas por circunstancias de hecho" (fracción I) y que son colectivos los intereses "transindividuales, de naturaleza indivisible, de los que sea titular un grupo, una categoría o una clase de personas ligadas entre si o con la parte contraria por una relación jurídica base" (fracción II).

De las definiciones, podemos concluir que estas categorías de intereses presentan dos características comunes: su supraindividualidad y su naturaleza indivisible ${ }^{20}$, que de acuerdo con BARBOSA, significa "que los interesados se hallan siempre en una especie de comunión tipificada por el hecho de que la satisfacción de uno solo implica necesariamente la satisfacción de todos, así como la lesión de uno solo constituye, ipso facto, la lesión de la entera comunidad" 21 . Presuponen también que la solución a los conflictos que pudieran generarse debe ser la misma para todos los integrantes del grupo.

Frente a estos intereses supraindividuales el Código brasileño se encarga también de definir los intereses individuales homogéneos, como aquellos que, "siendo de carácter individual tienen un origen común y que pueden ejercerse colectivamente para obtener una reparación individual de los daños sufridos por los consumidores" (fracción III) 22.

El origen de la protección de estos intereses está en la Constitución, puesto que en ella se reconocen algunos derechos que pueden tener trascendencia como intereses de grupo, como el derecho a la protección de la salud (artículo $19 \mathrm{n}^{\circ}$ 9) o el derecho a disfrutar de un medio ambiente adecuado para el desarrollo de la persona (artículo 19

\footnotetext{
${ }^{19}$ En este sentido PELLEGRINI (1984) pp. 30-31, distingue los intereses colectivos y difusos, y afirma que se consideran colectivos los intereses comunes a una colectividad de personas entre las que debe existir un vínculo jurídico, y difusos los intereses que sin existir un vínculo jurídico de por medio se basan en factores de origen fáctico y accidentales, como el habitar en una misma zona o consumir un mismo producto.

20 Opina De CAmargo (1991) p. 276, que en el caso de los intereses supraindividuales puede distinguirse una indivisibilidad en dos grados. La indivisibilidad que se refiere al derecho difuso es absoluta en función de la propia indeterminación de las personas que componen la comunidad titular del derecho o interés, mientras que en el caso de los intereses colectivos la indivisibilidad es relativa porque los miembros de la colectividad titular del derecho son determinados o fácilmente determinables.

${ }^{21}$ BARBosa (1992) p. 235.

22 Ello porque cada miembro del grupo es titular de un derecho individual de naturaleza divisible.
} 
$\left.\mathrm{n}^{\circ} 8\right)^{23}$. Su dimensión social viene dada especialmente en el artículo $1^{\circ}$ del texto constitucional, que se refiere a los grupos, y que dispone que "El Estado reconoce y ampara a los grupos intermedios a través de los cuales se organiza y estructura la sociedad y les garantiza la adecuada autonomia para cumplir sus propios fines especificos" 24 .

\subsection{CONCEPTO}

Para llegar a obtener una noción de interés supraindividual debe partirse del concepto general de interés y de interés jurídico ${ }^{25}$, analizando qué es lo que se añade a esta noción general para que el interés pueda ser calificado como interés supraindividual. La doctrina ${ }^{26}$ ha elaborado varios criterios para definir el concepto, según cuál es elemento destacado y en que se fundamenta la noción general de interés, atribuyéndoles un carácter nuevo, pudiendo así distinguir, en general, entre un criterio subjetivo, un criterio objetivo y un criterio normativo.

a) El criterio objetivo parte de la calificación del bien como idóneo para ser objeto del interés supraindividual. La existencia de un interés de este tipo viene dada por la aptitud de este bien para ser disfrutado por un grupo de sujetos, mientras que su carácter difuso no solo vendría dado por la referencia a un conjunto indeterminado de sujetos, sino también por la naturaleza del bien y el tipo de régimen jurídico a que esté sometido.

Se han formulado algunas críticas a este criterio, puesto que, al no exigir la existencia de una organización formal, se privilegian ciertas situaciones. También se

\footnotetext{
23 Sobre el particular, BERTELSEN (1998) p. 140, señala que la situación constitucional de los llamados derechos sociales es distinta, ya que sus titulares "son solo personas naturales, tienen la expectativa, que se considera valiosa y por ello es reconocida en el texto de las Constituciones, de acceder a ciertas prestaciones, las que pueden consistir en una acción en beneficio de los titulares, como es el caso de las acciones educativas y de salud, o en una dación, que es lo que ocurre en las prestaciones de la seguridad social".

${ }^{24}$ En concordancia con los artículos $4^{\circ}, 7^{\circ}$ y 23 del mismo texto constitucional.

25 Couture (1993) p. 344, define el interés como una "aspiración legítima, de orden pecuniario o moral que representa para una persona la existencia de una situación jurídica o la realización de una determinada conducta". No todos los intereses individuales o colectivos son susceptibles de considerarse jurídicamente relevantes. Solamente aquellos que el legislador selecciona como susceptibles de protección jurídica adquieren consagración constitucional o legal. La doctrina destaca algunos aspectos que deben tenerse en cuenta para considerar a un interés como jurídicamente relevante, considerando también que la tarea de reconocimiento de estos intereses responde a un estudio sociológico e histórico de los mismos. Se ha señalado que las normas entrañan una ordenación de los intereses dignos de considerar para su protección jurídica, y en función de lo anterior, la tarea del legislador consiste en armonizar los intereses en conflicto. Una vez producida a través de un proceso político la determinación de qué interés debe ser satisfecho con prioridad a los otros, el interés así recogido será un interés jurídico, que en definitiva viene a ser la satisfacción particular de una necesidad reconocida con carácter general por la norma. Por lo mismo, GutiéRREZ DE CABIEDES (1999) p. 46, ha definido el interés jurídico como aquel "que ha sido considerado por la norma como jurídicamente relevante y al que ésta brinda su protección (interés jurídicamente protegido), por considerar que se adentra en el orbe de lo jurídico y es digno de tutela jurídica".

${ }^{26}$ El concepto todavía es incierto y equívoco y se presta a bastantes confusiones. Para VigORITI (1979) p. 55 y ss., delimitar qué se entiende por interés supraindividual implica hacer una puntualización no solo terminológica, sino también sustancial, para preparar el terreno y las condiciones del acceso a la justicia de tales intereses.
} 
señala que esta concepción es reductiva ${ }^{27}$, porque exige como característica permanente la indivisibilidad del bien objeto del interés.

b) El posicionamiento doctrinal mayoritario se inclina por el criterio subjetivo, puesto que incluso cuando se habla de "interés supraindividual" se remarca el elemento plural y colectivo del elemento subjetivo. Se destaca que son colectivos, puesto que nadie es su titular, pero al mismo tiempo todos los miembros de un grupo o de una categoría determinada lo son ${ }^{28}$.

Se ha señalado que esta concepción resulta un tanto restrictiva, puesto que el problema también se plantea cuando no existe un ente que los represente ante los tribunales o cuando el grupo no está organizado. La presencia del ente portador solo afecta a la parte funcional del interés, es decir, a su gestión, que de este modo viene muy facilitada.

c) Un tercer criterio es el normativo, que se concreta en determinar si el ordenamiento reconoce un interés como jurídicamente relevante. Lo que caracterizaría a estos intereses es el hecho de permanecer ajenos a las normas jurídicas y mantenerse, por tanto, como intereses meramente fácticos. Los órganos jurisdiccionales no pueden proteger posiciones subjetivas que no hayan sido consideradas prevalentes y por tanto dignas de protección por el ordenamiento que deben aplicar.

Sin embargo, y sin perjuicio de que una gran cantidad de estos intereses no alcanzan reconocimiento normativo material y procesal, este dato no es útil para una definición con validez general, puesto que este tipo de intereses plantea problemas incluso después de haber sido reconocidos por el ordenamiento. El reconocimiento legal lo que hace es facilitar su defensa y protección.

Por lo anterior, autores como Bujosa, concluyen que el concepto de interés supraindividual puede ser explicado desde el criterio subjetivo y el objetivo, a pesar de sus dificultades de delimitación, puesto que con la utilización exclusiva de cualquiera de estos criterios se excluirían grupos de intereses que podrían ser calificados perfectamente como supraindividuales ${ }^{29}$.

27 Así, Vigoriti (1979) p. 56, critica esta posición porque señala que una cosa es el hecho de que las aspiraciones estén dirigidas hacia la consecución del mismo bien y otra es afirmar que la indivisibilidad objetiva deba ser una característica constante del bien al que aspiran estos intereses.

28 Un ejemplo clásico en este sentido es la definición de GIANNINI (1974) p. 23, cuando afirma que los intereses colectivos son aquellos que, en el ordenamiento positivo, se identifican a través de un criterio puramente subjetivo, que es el de su portador: son tales los intereses que tiene como portador (o centro de referencia) un ente exponencial de un grupo no ocasional.

29 Cfr. Bujosa (1995) pp. 77 y ss. Señala el autor que "en esta línea de combinación del elemento subjetivo y el elemento objetivo para definir este concepto se encuentra, por ejemplo, la famosa sentencia de la casación italiana, sez. un. $\mathrm{N}^{\circ} 2207$, de 8 de mayo de 1978, que definía los intereses difusos como "aquellos que por la idoneidad del objeto han de ser considerados en el ámbito exclusivamente individual -a causa de su naturaleza y del carácter de la normativa-, se refieren no al sujeto como individuo, sino como miembro de una colectividad más o menos amplia, coincidente en el límite con la generalidad de los ciudadanos, dando así lugar a una pluralidad de situaciones jurídicas análogas”. TROCKER (1987) p. 115, utiliza ambos criterios, cuando afirma que esta noción se refiere a una categoría particular de situaciones que en el ordenamiento positivo se identifican a partir de su portador (criterio subjetivo) y de la relación 
Existen también definiciones que emplean otros criterios. Almagro, por ejemplo, distingue tres planos: un plano subjetivo, referido a colectivos poco precisos en su composición, generalmente anónimos e indeterminados, aunque con dificultades determinables; un plano objetivo, en que el contenido del objeto se difumina, sea porque los mínimos no están fijados legislativamente, sea porque los obligados son múltiples y cada uno tiene que poner algo para el cumplimiento o realización del derecho y un plano formal de accionalidad o justicialidad imprecisa, puesto que el problema de la justicialidad abre a la doctrina el problema de nuevas formas de acceso a la justicia, porque al ser un grupo el afectado en determinada materia, desborda los esquemas clásicos del Derecho procesal ${ }^{30}$.

Se ha destacado también de este tipo de intereses su naturaleza conflictual, puesto que se trata normalmente de intereses incompatibles o contradictorios entre los que debe llevarse a cabo una función política de mediación y de coordinación, y un cierto grado de indeterminación, que implica una dificultad para circunscribir su difusión, puesto que se repiten y extienden a todos los miembros de una colectividad.

\subsection{NATURALEZA JURÍDiCA}

La naturaleza de estos intereses ha sido estudiada y muy debatida, aunque la mayor parte de la doctrina se inclina por reconducirla a los conceptos de derecho subjetivo o interés legítimo ${ }^{31}$, y los menos se inclinan por una tercera vía otorgándoles naturaleza autónoma.

a) Uno de las problemas más relevantes consiste en determinar si los intereses supraindividuales constituyen una suma de intereses individuales o bien una situación de ventaja única. $\mathrm{Al}$ respecto existen tres posiciones doctrinales ${ }^{32}$ : la primera corresponde a una perspectiva individualista y liberal de estos intereses, y considera que lo que se ha denominado "interés supraindividual" no existe como tal, sino que corresponde a una

entre el sujeto y el bien protegido (criterio objetivo), y por tanto, los intereses difusos "son aquellos intereses o situaciones jurídicas que pertenecen idénticamente a una pluralidad de sujetos más o menos determinada o determinable, eventualmente unificada más o menos estrechamente en una colectividad y que tienen por objeto bienes no susceptibles de apropiación y goce exclusivos”. GÓMEZ DE LIAÑo (1986), p. 558, también utiliza ambos criterios, puesto que por concepto amplio de intereses difusos entiende que se trata de "situaciones de hecho jurídicamente relevantes que integran o pueden integrar determinadas colectividades, categorías, grupos, clases de sujetos vinculados por una misma o común necesidad, y que se refieren a colectivos poco precisos en su composición, cuya titularidad, aunque individual, tiene su desarrollo en el grupo y social y sobre todo se defiende mejor y comprende bienes de uso general de difícil apropiación exclusiva".

${ }^{30}$ Cfr. Almagro (1983) pp. 638 y ss.

31 Así por ejemplo, se ha hablado de "derecho subjetivo colectivo" y de "interés legítimo colectivo". Lo cierto es que la polémica que genera la diferencia entre un interés legítimo y un derecho subjetivo pierde su sentido en el momento en que estos intereses son reconocidos constitucionalmente, puesto que alcanzan el mismo estatus de protección que un derecho subjetivo. Como señala Cordón (1992) p. 130, la fórmula constitucional de interés legítimo representa la forma en que acceden al proceso estos intereses de naturaleza social o colectiva. En este mismo sentido, vid. Almagro (1981) p. 403.

32 Cfr. Gutiérrez de Cabiedes (1999) pp. 73 y ss. 
agregación ideal de múltiples intereses individuales, y así "la simple suma de tales intereses no se transforma en un interés de grupo, pero cumple la importante función de aunar intereses para dotarles de tutela jurisdiccional" 33 .

La segunda posición concibe al interés supraindividual como un interés unitario en el que no se distinguen posiciones individuales; este interés recibe el nombre de "interés colectivo", que no constituye una suma de intereses, sino que una combinación de carácter indivisible en el sentido de que existe un bien apto para satisfacer la necesidad de una colectividad ${ }^{34}$. Un ejemplo de lo anterior lo constituye el artículo 32 de la Constitución italiana, que dispone que "la República tutela la salud como fundamental derecho del individuo e interés de la colectividad". Esta fórmula del "interés de la colectividad" no puede asimilarse ni al interés colectivo en sentido estricto ni al interés supraindividual propiamente tal, sino que hace referencia a un concepto de salud pública, considerada como un interés general, derivándose la confusión del mal uso del término "colectividad", puesto que se utiliza para referirse a la comunidad en general o bien a un grupo más o menos determinado de individuos, y de ahí entonces que el interés de la colectividad "se denomine, automáticamente, interés colectivo. Y se concluye, así afirmando que el interés colectivo es sinónimo del interés público"35.

Por último, la tercera posición constituye una postura intermedia, que postula que el interés supraindividual es una cualificación de intereses individuales que los eleva a una dimensión superior de la estrictamente individual ${ }^{36}$.

33 Alpa (1977) p. 283. En opinión del autor cabe preguntarse si el verdadero problema de los intereses difusos es su ejercicio práctico en el proceso por el hecho de permanecer desguarnecidos de tutela y por la inactividad del individuo afectado.

34 Bonaudi (1911) citado por Gutiérrez de Cabiedes (1999) pp. 75-76, escribía que "los intereses de tales colectividades especiales, que unas veces son constituidos simplemente por la suma y por la resultante de los singulares intereses individuales de sus componentes, otras, en cambio, aunque les comprenden, no se identifican con ellos...”.

35 GUtiérRez de CABiedes (1999) p. 77. No comparte ni la primera ni la segunda postura, porque no cree que el interés supraindividual constituya una situación jurídica única, ya que no puede aceptarse "la atribución de una supuesta titularidad única del interés a la 'colectividad'. De la referencia al 'grupo' como protagonista natural del fenómeno supraindividual (debe admitirse que los que comparten un determinado interés constituyen una cierta colectividad, comunidad o grupo diferenciado y dotado de una cierta identidad a nivel sociológico) no puede derivarse que la 'colectividad', entendida como algo autónomo y distinto de sus miembros, pueda ser considerada, en sentido técnico, titular del interés. Se puede hablar de un único interés solo en sentido traslaticio, para reflejar la comunidad de la aspiración y significar la relevancia de su dimensión colectiva. No existe una situación sustancial única de la cual sean cotitulares varios sujetos y, por ello, como se expondrá en su momento, en caso de deducirse la situación colectiva en juicio, no es necesaria la presencia coetánea de todos ellos en el proceso, es decir, que haya que trabarse litisconsorcio necesario entre todos los cointeresados".

36 Cfr. Gutiérrez de CABiedes (1999) pp. 78 y ss. Señala también que el problema central se encuentra en determinar si el interés supraindividual es atribuible, aunque sea de modo mediato, al individuo. Se inclina por una respuesta afirmativa, porque aunque el interés supraindividual refleja una realidad compartida por un grupo de sujetos en relación con un mismo bien, está constituido por una serie de situaciones subjetivas y personales. No se trata por lo tanto de intereses que no sea posible individualizar o que individualmente carezcan de relevancia jurídica, lo que en realidad sucede es que predominan si se consideran de manera global y su unificación hace que se les aprecie de modo particular. Tampoco comparte la 
El punto de partida para encontrar la solución al problema de la justiciabilidad de los intereses supraindividuales, con los correspondientes problemas que conllevan en lo que respecta a la legitimación para su defensa, es tener en cuenta que no se trata de intereses cuya individualización no sea posible, sino que, por su naturaleza particular, el ordenamiento les reconoce preeminencia si son globalmente considerados, lo que no quiere decir tampoco que individualmente carezcan de relevancia jurídica. El problema no consistirá en determinar si el interés existe o no, según pertenezca o no a un determinado sujeto o a un grupo de sujetos determinados, sino en ver quién es el portador legítimo de un interés que, aunque pertenezca a muchos, goza de autonomía y es considerado globalmente por el ordenamiento jurídico ${ }^{37}$.

b) Se ha discutido también si estos intereses tienen una naturaleza pública o priva$d a$, dividiéndose la doctrina en tres posiciones: la primera subsume el interés supraindividual en el ámbito privado, porque aunque es distinto del interés individual, no constituye un interés público ${ }^{38}$.

La segunda asimila los intereses supraindividuales al interés general o al interés público, puesto que a veces el término "colectivo" se utiliza para referirse a estos dos tipos de ámbitos, lo que se produce porque se usa este término de modo genérico o porque se sostiene expresamente que los intereses supraindividuales son intereses públicos; y la tercera postura sostiene que el interés supraindividual no se identifica ni con el interés público ni con el interés general, pero tampoco pertenece al ámbito de lo privado.

La tercera postura corresponde a quienes sostienen que el interés supraindividual ocupa una posición intermedia entre el ámbito público y el privado ${ }^{39}$.

Vigoriti postula un criterio distinto, y le resta importancia práctica a la discusión, ya que opina que no necesariamente un interés debe ser clasificado como público o privado. Muchos intereses que se consideraron como de naturaleza pública fueron luego

visión del interés supraindividual como una simple suma de intereses individuales y ello porque no se trata de posiciones jurídicas exclusivas, "sino que dan lugar a situaciones jurídicas análogas, compartidas, cualitativamente iguales, coincidentes con otras de igual contenido, que hacen referencia a diversos sujetos, unidos por el mismo fin. Dicho fin es perseguible por cualquiera de ellos, de modo autónomo, sin requerir la presencia ni el consenso de los demás, pues se actúa, en realidad, por una necesidad -y un interéspropio de cada sujeto, aunque su consecución no pueda sino satisfacer también a los demás sujetos que tienen ese mismo interés, esto es, una necesidad referida al mismo bien conseguido". Concluye por lo tanto que se trata de un interés referible a una colectividad, pero también a un individuo, a quien se protege no como individuo propiamente tal sino como miembro de esa colectividad y por pertenecer a la misma.

37 Cfr. Cordón (1997) p. 60.

38 Señala SANTORO (1963) p. 21, que "el interés colectivo -se utiliza, por tanto, en el sentido de supraindividual- que no sea un interés general de toda la colectividad organizada, aun siendo un interés individual, es, de por sí, un interés privado, no un interés público”. Se incluyen en esta tendencia todos los autores que consideran a estos intereses como estrictamente individuales.

39 En este sentido, GianNini (1991) p. 111, contempla la posibilidad de "intereses intermedios entre los públicos y los privados", puesto que esto correspondería a una cuestión de derecho positivo, ya que "nada impide que las normas creen especiales cualificaciones de intereses, con particulares efectos". Y agrega GÓMEZ DE LIAÑO (1986) p. 563, que "el interés colectivo está muy lejos de identificarse con el general, y mucho menos con el público, aunque tampoco puede afirmarse su pertenencia al campo privado”. 
tutelados por sujetos privados, como por ejemplo en el caso del medio ambiente o la salud. Señala que el problema de la naturaleza de estos intereses no se resuelve en términos de calificarlos como públicos o privados, sino que debe atenderse a una serie de circunstancias contingentes en un momento y en un lugar determinado ${ }^{40}$.

Para otros autores como Gutiérrez de Cabiedes, la discusión sobre la naturaleza pública o privada de estos intereses gira en torno a dos aspectos muy concretos: la primera es determinar si estos intereses son públicos o privados, lo que constituye una cuestión de titularidad y subjetivación, y la segunda es si se encuadran en un ámbito público o privado. En lo que respecta al primer aspecto, debe distinguirse el interés supraindividual del interés público, y con respecto a lo segundo, determinar en qué nivel se desenvuelven estos intereses.

Un interés supraindividual, en especial uno difuso, y el interés público, se diferencian en cuanto a su objeto, porque no siempre la pluralidad de sujetos a los que se refiere el interés difuso corresponde a la generalidad o totalidad de los miembros de una sociedad, ni tampoco el bien objeto del interés debe ser necesariamente de relevancia general. El interés difuso presenta además una característica que no presenta el interés público, y que está constituida por su posibilidad de fragmentación, puesto que de él emana el reconocimiento de situaciones jurídicas atribuibles a sujetos individuales o a organizaciones.

En cuanto a la segunda cuestión en discusión, esto es, el nivel en que se desarrollan los intereses supraindividuales, el autor señala que lo hacen en un ámbito intermedio que no es ni público ni privado, y tienen por tanto "una dimensión propia, que podría denominarse social a la que, en sentido genérico, se alude en la doctrina como 'colectiva'. Son intereses que originariamente son personales, pero que, por ser compartidos, comunes, no exclusivos, adquieren una relevancia superior, desde el punto de vista de su desenvolvimiento, siendo normalmente asumidos por personas u organizaciones sociales que los hacen valer" ${ }^{41}$.

\subsection{CARACTERIZACIÓN JURÍDICA}

Cabe preguntarse por qué en el caso de los intereses supraindividuales se habla de "intereses" y no de "derechos" 42 . La categoría tradicional de derecho es en algunos casos imprecisa y equívoca. Para Sgubbi, la forma técnico-jurídica de los intereses supraindividuales no puede ser la misma que la de un derecho subjetivo en la medida en que reenvíe a la idea de una posición de un individuo apreciado en abstracto y en términos

40 Cfr. VigORITI (1979) pp. 34-35.

41 Cfr. Gutiérrez De CABIEDES (1999) pp. 84 y ss. El autor hace referencia a la clasificación tripartita que hace Ihering de los intereses, en individuales, sociales y públicos.

42 Aunque muchos autores utilizan indistintamente estos términos para referirse a estos intereses. Ello porque una vez que alcanzan protección constitucional la polémica sobre su naturaleza pierde fuerza. A decir de GIDI (2003) p. 26, esta diferenciación entre derecho e interés se debe a la marcada influencia individualista de la dogmática jurídica tradicional. Ello porque la indivisibilidad del objeto y la imprecisión de la titularidad de los derechos supraindividuales no encajaría en la rígida delimitación conceptual del derecho subjetivo, y por eso se les denominó intereses. 
estrictamente individuales. Por ello es que es preferible valerse de una figura como la del "interés". Recchia afirma que el término "derecho" no puede identificarse normativamente con los de "interés" y de "necesidad", puesto que el primero hace referencia a una situación jurídica subjetiva constitucionalmente protegida, y los intereses colectivos no siempre tienen relevancia constitucional ${ }^{43}$.

Respecto de este tema, la doctrina también se encuentra dividida. Una posición señala que los intereses supraindividuales son calificables como derechos subjetivos o como intereses legítimos, ambos colectivos, puesto que el hecho de tener esta característica de colectivos no implica que no puedan ser reconducidos a una de estas categorías. Podrá ser un interés de calidad distinta, pero se tratará siempre de un derecho subjetivo colectivo o de un interés legítimo colectivo ${ }^{44}$.

Otros autores consideran en cambio que el concepto de interés supraindividual es un concepto jurídico autónomo, y se refieren a él como un tertium genus.

Esta calificación se ha adoptado a propósito de los intereses supraindividuales para referirse a fenómenos jurídicos distintos, es decir, utilizando como elementos de la comparación o relación entre objetos que no resultan equiparables. Así, algunos utilizan este término para explicar que los intereses difusos y colectivos ocupan esta posición alternativa con respecto al derecho subjetivo y al interés legítimo, y otros con referencia a las posiciones individuales y el interés público ${ }^{45}$.

También en lo que respecta a la caracterización jurídica existen diversas planteamientos. Algunos advierten la imposibilidad de aplicar a estos intereses los esquemas ordinarios de tutela puesto que a ellos no corresponde una forma de privilegio exclusivo o diferenciado, y por lo tanto no podrían equipararse ni al derecho subjetivo ni al interés legítimo. Al derecho subjetivo porque la tutela no es directa y absoluta, sino ocasional y mediata y, además, la titularidad de un interés difuso no confiere una facultad de disposición directa. Respecto del interés legítimo, se señala que la diferencia que presenta con el interés difuso es de carácter procesal, puesto que el interés difuso no otorga poder de acción, como sí sucede en el caso del interés legítimo, al que es inherente. Es decir que el interés difuso no es un interés legítimo, sino un interés de hecho, cuya actuación se desarrolla en la función administrativa. Desde el punto de vista procesal se manifiesta, a tal nivel, el defecto absoluto de jurisdicción ${ }^{46}$. Siguiendo este criterio, la jurisprudencia italiana, durante mucho tiempo, situó a los intereses supraindividuales en el ámbito de los intereses simples o de hecho y muchas veces haciendo sinónimos los términos.

En España, Lozano-Higuero rechaza la posibilidad de que los intereses supraindividuales puedan considerarse como intereses legítimos, ya que considera que "el concep-

\footnotetext{
43 Cfr. Gutiérrez de Cabiedes (1999) pp. 88-89.

${ }^{44}$ Cfr. Vigoriti (1979) pp. 24-32.

45 Sobre este punto, cfr. GUTIÉRREZ de Cabiedes (1999) pp. 92-93.

46 Cfr. LANDi (1991) p. 46. GutiéRrez DE CABIEDEs (1999) p. 94, discrepa de la tesis citada, puesto que además de considerarla poco clara, señala que LANDI expone luego que "la inversión del interés de hecho en interés difuso tiene lugar con la atribución de la tutela jurisdiccional”, lo que para el autor resulta contradictorio con las afirmaciones anteriores de este autor italiano.
} 
to de interés legítimo debe ser obviado en la teoría -y legislación- de los intereses difusos, hasta el punto de que la situación subjetiva de ventaja jurídicamente relevante en estas nuevas dimensiones de tutela ya no se califica como interés a secas, sino de derecho, o bien, de modo equivalente, estimando que deben precisarse como derechos, antes que simples intereses, o bien, aceptar que hay intereses que por su cualidad merecen ser atendidos de inmediato sin importar el carácter que inviste la persona o el grupo que para sí los reclame” ${ }^{37}$.

\section{LOS INTERESES SUPRAINDIVIDUALES EN PARTICULAR: EL INTERÉS DIFUSO Y EL INTERÉS COLECTIVO}

\subsection{Planteamiento}

En el estudio de los intereses supraindividuales la labor más profunda fue desarrollada, en su origen, por la doctrina ${ }^{48}$. El trabajo ha girado en torno a la elaboración de los conceptos de interés difuso ${ }^{49}$ e interés colectivo, y a los criterios de reconocimiento y tutela de estos intereses, plasmándose en posiciones diversas que, pese a las diferencias, se orientan mayoritariamente, a que no constituyen un tertium genus respecto de las figuras tradicionales del interés legítimo y del derecho subjetivo.

47 LozAnO-Higuero y Pinto (1998) p. 185.

48 En cuanto al tratamiento de este tema, la doctrina italiana ha sido muy prolífica. Una obra muy completa es la de VigORITI (1979) ya reseñada.

${ }^{49} \mathrm{El}$ centro de la discusión en cuanto a la definición de "interés difuso" radica necesariamente en qué debe entenderse por "difuso". El Diccionario de la Lengua Española define "difuso" como ancho, dilatado, con lo que no aporta demasiado a la discusión, y el Diccionario de Uso Español lo define como "aquello que hace referencia a algo que es extenso y poco preciso". Para ACOSTA (1995) p. 45, el concepto vendrá determinado "por dos notas o criterios diferenciadores, a saber: su pertenencia a un grupo carente de organización y el carácter anónimo del mismo. Así, tomando como base ambos rasgos -organizativo y subjetivo- entendemos por interés difuso el interés propio, jurídicamente reconocido, de un grupo social o colectividad indeterminada de sujetos, desprovista de una organización que los tome para sí enteramente y tenga capacidad para su defensa, cuya tutela jurisdiccional responde a eventuales iniciativas meramente individuales". El autor extrae de las posiciones de Giannini y Vigoriti los criterios diferenciadores de intereses difusos y colectivos, esto es, los criterios organizativo y subjetivo. SÁNCHEZ (1980) p. 118, considera que el interés difuso "es el interés jurídicamente reconocido de una pluralidad indeterminada o indeterminable de sujetos que, en potencia, pueden ser incluso todos los que integran la comunidad general de referencia, el ordenamiento general cuya normativa protege tal tipo de intereses". Para LOZANOHiguero y PinTo (1998) pp.149-150, el interés difuso es "el interés de un sujeto jurídico en cuanto compartido -expandido-compartible-expandible- por una universalidad, grupo, categoría, clase, o género de los mismos; cuyo disfrute, ostentación y ejercicio son esencialmente homogéneos y fungibles, y que adolece de estabilidad u coherencia en su vinculación subjetiva, así como de concreción normativa orgánica en sus tutelas material y procesal". Puede entonces concluirse, que el término "difuso" alude a una “escasa precisión jurídica" en relación al vocablo "interés”. Esta difusión o falta de precisión se manifiesta en el plano subjetivo, objetivo y formal del modo que sigue: subjetivamente, la difusión se manifiesta en un doble aspecto, ya que se trata de intereses referidos a colectivos poco precisos en su composición, generalmente anónimos e indeterminados o determinables con dificultades, y en la medida en que estos intereses se densifican en derechos constitucionalmente reconocidos, la titularidad de estos derechos que aunque individuales tienen su proyección y desarrollo en el grupo social, motivan cuestiones de filosofía jurídica todavía abiertas entre individualismo social y socialismo. 
Se distinguen tres grupos de situaciones de relevancia supraindividual: aquellas en las que hay más de un titular activo o pasivo de la relación jurídica material, pero cuyos problemas de tutela procesal pueden resolverse mediante instituciones clásicas (litisconsorcio, intervención de terceros); aquellos casos en que un grupo más o menos amplio de personas se encuentran unidas por un vínculo jurídico; y por último, los intereses comunes a una colectividad de personas que no necesariamente se encuentran jurídicamente vinculadas, sino que, más bien, el interés que se trata de tutelar se basa en datos de hecho, siendo muy difícil la delimitación de los componentes del grupo precisamente por la inexistencia de este vínculo jurídico ${ }^{50}$.

El primer grupo se ajusta a las estructuras clásicas del derecho y por lo tanto escapa a esa nueva forma de considerar las situaciones jurídico-subjetivas de ventaja a través de la característica de la relevancia supraindividual. La trascendencia social es importante en el caso del segundo y tercer grupo, en los que se apunta la distinción entre intereses difusos y colectivos.

\subsection{El INTERÉS DIFUSO Y EL INTERÉS COLECTIVO}

Respecto de estas categorías de intereses puede decirse que comparten los mismos problemas jurídicos y que ambas se refieren a bienes de carácter indivisible ${ }^{51}$, pero con una distinción fundamental: los intereses difusos se refieren al sujeto no como individuo sino como miembro de un grupo que puede ser más o menos amplio, pero indeterminado o de muy difícil determinación, mientras que los intereses colectivos atañen a grupos delimitados en que los miembros se encuentran determinados o son fácilmente determinables.

Son varios los criterios que se han propuesto para diferenciar los intereses difusos y los colectivos:

a) Uno de ellos atiende a si los miembros del grupo están vinculados por circunstancias de hecho o bien ligados por una relación jurídica.

b) Giannini considera que los intereses colectivos se determinan sobre la base de un criterio subjetivo, es decir, atendiendo al portador del interés, de modo que son aquellos que tienen como portador o centro de referencia un ente exponencial de un grupo no ocasional. De ellos se diferencian los que no tienen portador, o adespoti, como los denomina este autor ${ }^{52}$.

\footnotetext{
50 Cfr. BARbosa (1979) pp. 2674-2677.

51 En este sentido, señala FERRER (2004) p. 13, que la distinción entre situaciones difusas y colectivas no siempre es clara puesto que ambas obedecen al mismo fenómeno. Por la circunstancia de ser la indivisibilidad una nota esencial de estos intereses no pueden ser considerados como una suma de intereses individuales porque pertenecen a una colectividad.

52 Giannini (1974) p. 101.
} 
c) Se ha señalado también que los intereses difusos presentan una nota de mayor distancia que los intereses colectivos, y por lo tanto los primeros resultan más neutrales que los segundos 53 .

d) Otro factor que se ha considerado es el de la unificación de los intereses. En este sentido, Nigro define los intereses difusos como "intereses que pertenecen por igual a una pluralidad de sujetos más o menos amplia y más o menos determinada o determinable, que puede ser o no unificada o unificada más o menos estrictamente, en una colectividad. En este último caso son intereses colectivos" 54 .

e) Otros autores ven en el criterio de la organización el elemento que determina la diferencia fundamental entre estos intereses. Así, Vigoriti expresa que ambas fórmulas se refieren a una pluralidad de situaciones de ventaja de carácter individual, pero que en el primer caso, existe una organización que asegura la unidad en el tratamiento de los intereses correlacionados y unidad de efectos de la resolución jurisdiccional, y en el caso de los segundos los intereses están atomísticamente considerados y carecen de los instrumentos necesarios para ser valorados de manera unitaria. Por lo tanto, para que estemos frente a un interés colectivo, necesariamente debe existir alguna forma de organización, y este es el elemento esencial que distingue a un interés colectivo de uno difuso. La denominación intereses difusos "estaría reservada a aquellas posiciones de ventaja reconocidas a los particulares por el ordenamiento, de igual contenido y hasta dirigidas al mismo fin (mismo bien jurídico), pero no organizados y, por consiguiente, no ligados por vínculos capaces de hacerles perder relevancia jurídica, como posiciones individuales, para hacerles asumir relieve como elementos de un interés más amplio" 55 .

f) Denti se manifiesta contrario al criterio organizativo y estima que la diferencia radica en el carácter corporativo de los intereses colectivos, que serían intereses de categoría en contraste con los difusos, que vendrían a ser intereses generales ${ }^{56}$.

g) Algunos se fijan en el reconocimiento normativo que distinguiría a ambas categorías de intereses, criterio que ha sido adoptado en España por Lozano-Higuero, quien lo considera como un elemento definitorio del interés difuso ${ }^{57}$.

\footnotetext{
53 Este criterio ha sido adoptado en España por Almagro (1982-83) p. 96, que señala que "lo típico de estos intereses sociales o colectivos que se denominan difusos es su acotación por grupos o clases o sectores de manera más o menos extensa". Y en razón de esta distribución de los intereses en clases o grupos "surgen conflictos a veces entre la satisfacción de los intereses de un grupo respecto de otros, lo que lleva a poner de relieve otra nota que acompaña al concepto de intereses difusos la conflictualidad".

54 Nigro (1978) p. 115, y en este mismo sentido, SÁnCHEZ (1980) p. 116.

55 Vigoriti (1979 p. 42. Agrega Gutiérrez De Cabiedes (1999) p. 103, que esta concepción del interés difuso es la que más se aleja de las connotaciones publicistas o colectivistas, puesto que para el autor italiano, si los intereses no se organizan permanecen en la esfera individual, aunque coincidan en contenido.

56 Denti (1983) p. 307, citado por GutiérRez De CABIedes, P., La tutela jurisdiccional..., op. cit., p. 104, quien opina de manera contraria a la asimilación que Denti hace de los intereses colectivos y los intereses generales.

57 Cfr. Lozano-Higuero y Pinto, M. (1998) p. 155, donde se establece una definición de interés difuso de acuerdo con la cual este adolece "de concreción normativa orgánica en sus tutelas material y procesal". Insiste en sus últimas publicaciones "De nuevo sobre la tutela de los intereses difusos...”, op.
} 
h) Barrios de Angelis cree que el interés puede ser individual o grupal, según corresponda a un individuo o a un grupo bien delimitado. Cuando el interés corresponde a un grupo indeterminado de personas, entonces puede comenzar a hablarse de interés difuso y colectivo. Así, "es la dimensión del grupo subjetivo lo que hace colectivo a un interés, pero es la indeterminación, la falta de límites precisos en cuanto a la identificación de las personas que lo componen, lo que convierte a ese interés en difuso. Por lo tanto, el interés difuso se caracteriza por corresponder a los sujetos de un grupo indeterminado". Excluye también de la categoría de interés difuso a toda colectividad con personalidad jurídica reconocida, lo que lleva a una confusión entre la "colectividad" como pluralidad de sujetos interesados y una organización social personificada, que por tener interés sobre el bien de que se trate puede emprender acciones en defensa del mismo $^{58}$.

i) El Derecho brasileño desarrolla otro criterio, referido a la vinculación jurídica, siendo colectivos "aquellos intereses comunes a una colectividad de personas y solamente a ellas, cuando existe un vínculo jurídico entre los integrantes del grupo: la sociedad mercantil, el condominio, la familia, los entes profesionales, el mismo sindicato, dan margen a que surjan intereses comunes, nacidos en función de una relación base que une a los miembros de las respectivas comunidades y que, no confundiéndose con los intereses estrictamente individuales de cada sujeto, permiten su identificación”, y difusos "aquellos que, no fundándose en un vínculo jurídico, se basan en datos de hecho genéricos y contingentes, accidentales y mudables: como habitar en la misma región, consumir los mismos productos, vivir en determinadas circunstancias socioeconómicas, someterse a particulares empresas" 59 .

Nuestra legislación también ha querido hacerse cargo de la consagración y protección de los intereses colectivos y difusos, y es así que con fecha 4 de mayo de 2004 se aprobó la Ley no 19.955, de Protección del Consumidor, publicada en el Diario Oficial con fecha 14 de julio de ese mismo año. Esta Ley introduce importantes reformas a la Ley 19.496, de 7 de marzo de 1997, y entre sus principales novedades se encuentra la creación de un procedimiento especial para la defensa de estos intereses, que se rige por las reglas del juicio sumario con algunas especialidades ${ }^{60}$.

La Ley, en su artículo 50, define lo que debe entenderse por acciones de "interés individual", "interés colectivo" e "interés difuso".

cit., pp. 309-313, y en "Legitimación. Protección jurisdiccional...", op. cit., p. 187, en los que habla de "deficiente tutela procesal" y de "insuficiente o deficiente regulación o cobertura normativa", que el autor denomina "hiporregulabilidad" y "hipojusticiabilidad".

58 BARRIOS DE ANGELIS (1983) p. 126.

59 PELlegrini (1988) p. 707.

${ }^{60}$ Con anterioridad a la dictación de esta ley en la legislación chilena se contemplaba la posibilidad de que estos intereses accedieran al proceso a través del artículo 18 C.P.C., que dispone que "en un mismo juicio podrán intervenir como demandantes o demandados varias personas siempre que se deduzca la misma acción, o acciones que emanen directa e inmediatamente de un mismo hecho, o que se proceda conjuntamente por muchos o contra muchos en los casos que autoriza la ley". Cfr. en este sentido ROMERO (1999) pp. 311 a 335. 
Señala que "son de interés individual las acciones que se promueven exclusivamente en defensa de los derechos del consumidor afectado", que "son de interés colectivo las acciones que se promueven en defensa de derechos comunes a un conjunto determinado o determinable de consumidores, ligados con un proveedor por un vinculo contractual" 61 y que "son de interés difuso las acciones que se promueven en defensa de un conjunto indeterminado de consumidores afectados en sus derechos".

Para diferenciar al interés colectivo del difuso se ha utilizado el criterio de determinación de los miembros del grupo titular de ese interés, encontrándonos ante un interés colectivo si los miembros del grupo son determinados o son fácilmente determinables y un interés difuso si se trata de un conjunto indeterminado de consumidores afectados.

A modo de conclusión, podemos destacar varios aspectos: los intereses colectivos y difusos no presentan diferencias esenciales, puesto que hacen referencia a un mismo fenómeno jurídico y a situaciones jurídicas con una misma naturaleza y estructura, y que comportan similares problemas procesales. Sin perjuicio de lo señalado, considera que los factores determinantes al momento de diferenciarlos son la extensión y la determinación de los sujetos interesados, al que puede agregarse el de la vinculación entre los miembros del grupo o de la colectividad interesada. De esta forma, "cuando el grupo de personas que se encuentran de forma común y simultánea en una misma situación jurídica con respecto a un bien que todos ellos disfrutan sea determinado o determinable en su composición, en sus miembros, puede hablarse de interés colectivo. Cuando, por el contrario, se trate de una comunidad de sujetos amplia e indeterminada o muy difícilmente determinable puede hablarse de interés difuso" 62 .

\subsection{LOS DERECHOS INDIVIDUALES HOMOGÉNEOS O PLURISUBJETIVOS}

Corresponde a una categoría de intereses que ha sido elaborada en los países del Common Law y por la legislación brasileña, que como hemos señalado, la introduce en el Código del Consumidor de 1990. Son derechos individuales que por efectos prácticos se hacen "accidentalmente colectivos" 63 , y que han sido definidos como "una compila-

${ }^{61}$ Nos parece poco apropiada la definición que entrega el legislador de "acciones de interés colectivo", puesto que no ha captado la verdadera esencia del interés colectivo y su diferencia esencial con el interés difuso. El interés colectivo se refiere a comunidades unificadas, más o menos determinadas en sus componentes, que se identifica en base a características o aspiraciones comunes. Lo anterior no implica que nos encontremos frente a una suma de intereses individuales, sino que enfrentamos un interés que pertenece a una pluralidad de personas en un bien que puede satisfacer una necesidad común. Si damos cuenta de lo que se ha mencionado a propósito del interés colectivo, se hace referencia por la doctrina a un vínculo de tipo jurídico -cualquiera- entre los miembros del grupo titulares de este interés, y no a un vínculo de naturaleza contractual que ligue al grupo con un sujeto externo a dicho grupo. Creemos que resulta criticable la exigencia de un vínculo contractual entre el conjunto de consumidores titulares del interés colectivo y un proveedor, no solo porque la exigencia contraría la naturaleza esencial del interés colectivo, sino porque restringe marcadamente el campo de protección jurisdiccional de dichos intereses.

62 Gutiérrez de Cabiedes (1999) p. 109.

63 Cfr. Barbosa (2000) pp. 195-196. Los distingue así de los supraindividuales, a los que califica como "esencialmente colectivos", citado por WATANABE (2003) p. 3. Este mismo autor los califica como "ontológicamente individuales, pero que son tutelados colectivamente, por razones de estrategia de tratamiento de conflictos". 
ción de derechos subjetivos individuales, marcados por la nota de divisibilidad, del cual es titular una comunidad de personas indeterminadas más determinables, cuyo origen está en alegaciones de cuestiones comunes de hecho o de derecho"64.

Estos intereses se distinguen de los difusos y colectivos en que aquellos son verdaderos derechos individuales, privativos e indisponibles por terceros, pero que pueden existir en número plural y tener un origen fáctico común y un contenido sustantivo homogéneo ${ }^{65}$.

Presentan dos características esenciales para su tratamiento colectivo: su homogeneidad, que le viene dada por su origen $\operatorname{común}^{66}$ y su divisibilidad, puesto que nos encontramos ante derechos que pueden ejercerse individualmente, pero respecto de los cuales resulta más conveniente su defensa colectiva.

Agrega Pellegrini que la distinción fundamental se manifiesta en que en los intereses supraindividuales la solución del litigio es la misma para todos, debido a la indivisibilidad del objeto del proceso y en los segundos, en cambio, la solución no es la misma para todos, precisamente porque el objeto del proceso es divisible ${ }^{67}$.

La diferencia entre los intereses supraindividuales y los plurisubjetivos tiene mucha importancia desde el punto de vista práctico puesto que su tratamiento procesal es distinto por tratarse los segundos de derechos subjetivos clásicos, lo que implica que en lo que respecta a la legitimación, los límites subjetivos de eficacia de la sentencia y la indemnización de los perjuicios dependerán de las circunstancias personales del titular del derecho ${ }^{68}$.

Fecha de recepción: 24 de enero 2006 Fecha de aceptación: 24 de abril 2006

\footnotetext{
${ }^{64}$ GIDI (2003) p. 35.

65 Cfr. GutiérRez de Cabiedes (1999) p. 441. Señala que por ejemplo, la difusión de una publicidad engañosa o la comercialización de un producto defectuoso dan lugar a un interés difuso, mientras que la falta de higiene o seguridad en una fábrica dará lugar a un interés colectivo. Serán derechos individuales plurales aquellos de que son titulares quienes han adquirido un bien que no responde a las cualidades anunciadas o contratadas.

66 No es requisito que entre las personas titulares de este tipo de derechos exista una relación jurídica anterior, puesto que el vínculo con la parte contraria nacerá precisamente de la lesión, relación que además es individual y que afectará de modo distinto la esfera jurídica de cada uno de ellos. El origen común en todo caso puede ser más o menos remoto. Mientras más remoto menos homogéneos serán estos derechos. Tampoco este origen común implica necesariamente una unidad de hecho temporal, lo que significa que no es necesario que el hecho creador de los derechos sea el único o el mismo en todos los derechos. Lo esencial será que nos encontremos ante situaciones jurídicamente iguales, aunque los hechos sean diferentes.

67 Cfr. Pellegrini (1994), pp. 106-114. En sentido contrario GutiérRez DE CABIEDES (1999) pp. $107-$ 108, para quien la distinción no debe basarse en el criterio de la divisibilidad, sino en la existencia o inexistencia de monopolio en la disposición material y procesal de la situación jurídica que se tutela.

${ }^{68}$ Hay que estar también a la forma en que se formula la solicitud de tutela jurisdiccional y los fundamentos de la demanda colectiva, para saber si nos encontramos ante una verdadera demanda para la tutela de intereses supraindividuales o si bien se trata de tutela intereses individuales homogéneos.
} 


\section{BIBLIOGRAFÍA CITADA}

Acosta Estévez, José (1995): Tutela procesal de los consumidores (Barcelona, Bosch) 209 pp.

Almagro Nosete, José (1981): "Cuestiones sobre legitimación en el proceso constitucional de amparo”, en AA.VV., El Tribunal Constitucional (Madrid, Dirección General de los Contencioso-Administrativo; Instituto de Estudios Fiscales).

Almagro Nosete, José (1982): “Tutela procesal ordinaria y privilegiada (jurisdicción constitucional) de los intereses difusos", en Revista de Derecho Politico, $\mathrm{N}^{\circ} 16$, pp. 93-108.

Almagro Nosete, José (1983): “La protección procesal de los intereses difusos en España”, en Justicia, $\mathrm{N}^{\circ} 1$, pp. 69-86.

AlPA, Guido (1977): Tutela del consumatore e controlli sull'Impresa (Bologna, Il Mulino).

Barbosa Moreira, José Carlos (1979): "A ação popular do Direito brasileiro como intrumento de tutela jurisdiccional dos chamados 'intereses difusos' ", Studi in onore de Enrico Tullio Liebman, vol. IV: pp. 2673-2692.

Barbosa Moreira, José Carlos (1992): "La iniciativa en la defensa judicial de los intereses difusos y colectivos (un aspecto de la experiencia brasileña)", Revista Uruguaya de Derecho Procesal, $\mathrm{N}^{\circ} 2$.

BARRIOS DE ANGELIS, Dante (1983): Introducción al estudio del proceso. La psicología y la sociología del proceso. El Ombudsman (La defensa de los intereses difusos), (Buenos Aires, Depalma).

Berizonce, Roberto (2003): "Presentación”, VV.AA. (coord. Gidi, Antonio y FeRRER MAC-GREGOR, Eduardo) La tutela de los derechos difusos, colectivos e individuales homogéneos. Hacia un Código Modelo para Iberoamérica, (México, Ed. Porrúa) $756 \mathrm{pp}$.

BERTELSEN RepetTO, Raúl (1998): "El recurso de protección y el derecho a vivir en un medio ambiente libre de contaminación. Examen de 15 años de Jurisprudencia", Revista Chilena de Derecho, vol. $25 \mathrm{~N}^{\circ}$ 1: pp. 139-174.

Bonet NaVArro, Ángel (1989): "Protección eficaz y acceso a la justicia de los consumidores", Estudios sobre Consumo, $\mathrm{N}^{\circ} 16$.

BUjOSA VADELL, Lorenzo (1995): La protección jurisdiccional de los intereses de grupo (Barcelona, Bosch).

Cappelletti, Mauro (1995): "Formaciones sociales e intereses de grupo frente a la justicia civil", Boletín Mexicano de Derecho Comparado, $\mathrm{N}^{\circ} 83$.

Cordón Moreno, Faustino (1989): "El acceso a la justicia civil de los derechos de los consumidores", Estudios sobre Consumo, $\mathrm{N}^{\circ} 16$.

CORdón Moreno, Faustino (1992): El proceso de amparo constitucional, 2a ed. (Madrid, La Ley).

Cordón Moreno, Faustino (1997): “De nuevo sobre la legitimación”, Revista de Derecho Procesal, $\mathrm{N}^{\circ} 1$. 
Couture, Eduardo (1993): Vocabulario Jurídico: con especial referencia al Derecho Procesal positivo vigente uruguayo (Buenos Aires, Depalma).

De Camargo Mancuso, Rodolfo (1991): Comentários ao código de proteção do consumidor (Saraiva, São Paulo).

DE LUCAS, Javier (1993): El concepto de solidaridad (México, Fontamara).

Fairén Guillén, Víctor (1990): Doctrina general del Derecho Procesal. Hacia una teoría y ley procesal generales (Barcelona, Bosch).

FERRER MAC-GREGOR, Eduardo (2004): Juicio de amparo e interés colectivo: la tutela de los derechos difusos y colectivos (México, Porrúa).

Denti, Vittorio (1983): "Interessi Diffusi”, Novissimo Digesto Italiano, Apéndice, vol. IV (Torino, Utet).

Giannini, Massimo Severo (1974): "La tutela degli interessi collettivi nei procedimenti amministrativi", Rivista di Diritto Processuale Civile.

Giannini, Massimo Severo (1991): Derecho Administrativo (trad. Luis OrTegA, Madrid, Ediciones del Ministerio para las Administraciones Públicas).

Gidi, Antonio (2003): "Derechos difusos, colectivos e individuales homogéneos", VV.AA. (coord. GIDI, Antonio y Ferrer MAC-Gregor, Eduardo) La tutela de los derechos difusos, colectivos e individuales homogéneos. Hacia un Código Modelo para Iberoamérica (México, Porrúa).

GÓmeZ de Liaño GONZÁlez, Fernando (1986): "La legitimación colectiva y el artículo 7º de la Ley Orgánica del Poder Judicial”, Justicia $N^{\circ} 86$, pp. 549-576.

GONZÁlez VAQUÉ, Luis (1991): "El Derecho de consumo: ¿una disciplina jurídica autónoma?", Estudios sobre Consumo, $\mathrm{N}^{\circ} 22$.

GUTIÉRREZ De CABIEDes, Pablo (1999): La tutela jurisdiccional de los intereses supraindividuales: colectivos y difusos (Navarra, Aranzadi).

LANDI, Pasquale (1991): La tutela processuale dell'ambiente (art. 18 della lege 8 luglio 1986, N³49), (Padova, Cedam).

LozAnO-Higuero y PinTo, Manuel (1998): “Legitimación, protección jurisdiccional de los intereses difusos", VV.AA. (coord. Manuel MORÓN PALOMINO) El proceso civil y su reforma (Madrid, Colex), pp. 169-190.

Nigro, Mario (1978): Giustizia amministrativa (Bologna, Il Moulino), 357 pp.

Pellegrini Grinover, Ada (1984): "A problemática dos interesses difusos", A tutela dos interesses difusos, (Sao Paulo, Max Limonad).

Pellegrini Grinover, Ada (1988): "Acciones colectivas para la defensa del ambiente y de los consumidores (La ley brasileña N 7347 de 24 de julio de 1985)", Revista de Derecho Procesal, $\mathrm{N}^{\circ} 3$, pp. 705-724.

Pellegrini Grinover, Ada (1994): "I processi collettivi del consumatore nella prassi brasiliana", Rivista di Diritto Processuale, $\mathrm{N}^{\circ} 4$.

Pellegrini Grinover, Ada (2003): "Introducción”, VV.AA. (coord. Gidi, Antonio y Ferrer MaC-Gregor, Eduardo), La tutela de los derechos difusos, colectivos e individuales homogéneos. Hacia un Código Modelo para Iberoamérica (Porrúa, México).

Rodríguez López, Ricardo (1990): "Tutela jurisdiccional de los derechos de los consumidores y usuarios”, Actualidad Civil, N56: pp. 473-506. 
SÁnCHez Morón, Miguel (1980): La participación del ciudadano en la Administración Pública (Madrid, Centro de Estudios Constitucionales) 292 pp.

SAntoro Passareli, Francesco (1963): Nociones de Derecho del Trabajo (trad. SuÁREZ GonZÁlez, $14^{a}$ ed., Madrid, Instituto de Estudios Políticos).

Trocker, Nicolo (1987): "Gli interessi difussi nell' opera della giurisprudenza", Rivista Trimestrale di Diritto Procesuale, pp. 1112-1155.

VASAK Karel (1982): "Human rights: as a legal reality", The international dimensions of human rights (ed. Karel VASAK, Connecticut, Greenwood Press).

VIGORITI, Vincenzo (1979): Interessi colletivi e processo. La legitimazione ad gire (Milano, Dott. A. Giuffrè Editore). 
